
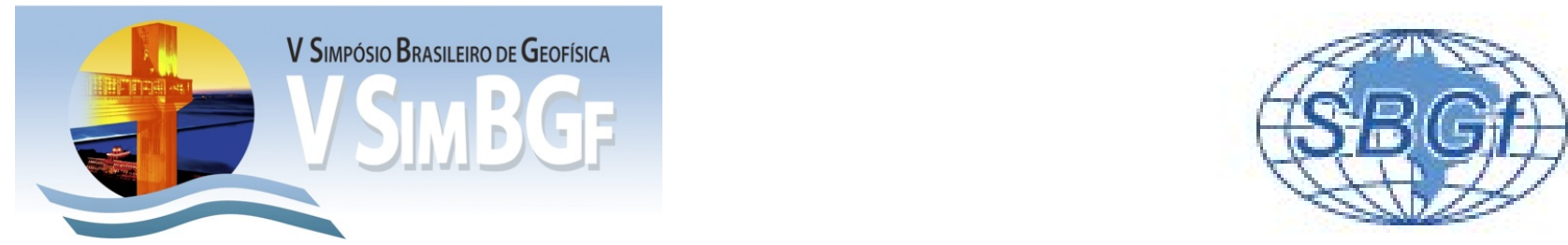

\title{
Detecção de difrações através de painéis de coerência
}

Susanne Taina Ramalho Maciel, FUP - Universidade de Brasilia e Ricardo Biloti, Universidade Estadual de Campinas

Copyright 2012, SBGf - Sociedade Brasileira de Geofísica Este texto foi preparado para a apresentação no $V$ Simpósio Brasileiro de Geofísica, Salvador, 27 a 29 de novembro de 2012. Seu conteúdo foi revisado pelo Comitê Técnico do $V$ SimBGf, mas não necessariamente representa a opinião da SBGf ou de seus associados. É proibida a reprodução total ou parcial deste material para propósitos comerciais sem prévia autorização da SBGf.

\section{RESUMO}

Revisamos a detecção de difrações em seções de afastamento comum a partir de painéis de coerência. $O$ método constitui um procedimento automático, que utiliza medidas de coerência e as principais propriedades dinâmicas e cinemáticas das ondas difratadas para a detecção tanto da posição de pontos difratores, quanto a velocidade do meio nestas regiões. O método é aplicado em seções de afastamento comum simuladas de modelos sintéticos.

\section{INTRODUÇÃO}

Um dos problemas mais importantes na interpretação de dados sísmicos é a localização de estruturas pontiagudas, como falhas, canais, descontinuidades geológicas entre outras. Estas estruturas, quando possuem dimensões menores do que o comprimento da onda acústica emitida em um levantamento sísmico, espalham a energia ao serem atingidas pelo campo de onda, gerando difrações.

As difrações possuem características distintas das ondas que são refletidas. Entre as diferenças, destaca-se o fato de que as amplitudes observadas em ondas difratadas são proporcionalmente menores do que as amplitudes das ondas refletidas, e por este motivo as difrações em geral são tratadas como ruído no processamento sísmico tradicional. A supressão da informação contida na onda espalhada, no entanto, suaviza descontinuidades abruptas no imageamento, o que dificulta a localização exata de estruturas importantes.

A ideia central do trabalho proposto é enriquecer o processamento sísmico tradicional de reflexões, acrescentando na construção do modelo de velocidades para a migração, pontos de controle onde são identificadas estruturas espalhadoras. Estes pontos de controle são determinados a partir do processamento de uma seção sísmica pré-processada de tal forma onde as difrações são vistas como informação, e as reflexões como ruído. Nesta mesma linha de pesquisa, Fomel et al. (2007), Sava et al. (2005) e Khaidukov et al. (2004) propõem técnicas para o imageamento e análise de velocidades de seções onde as difrações são vistas como informação.

O modelo é ajustado por uma base de B-splines, onde os coeficientes são encontrados através de uma abordagem de quadrados mínimos. Pesos maiores são dados aos pontos de controle, encontrados pelos dados de difração.

As propriedades dinâmicas da onda difratada são explicadas no trabalho de Trorey (1970), que expõe uma fórmula fechada para sua propagação, por onde é possível mostrar matematicamente que, para difrações geradas a partir de um truncamento de um refletor plano, a fase da onda difratada muda em $180^{\circ}$ nas quinas do refletor. Nesta região, sua amplitude é metade da amplitude da onda refletida, e nas regiões mais afastadas do ponto difrator há um decaimento da amplitude. A partir destas constatações, e das propriedades cinemáticas das difrações, Landa et al. (1987) propõem um algoritmo de detecção de difrações em uma seção de afastamento comum, a partir da construção de seções-D. Neste trabalho, utilizamos as seções-D em uma versão adaptada, para a construção de modelos de velocidade onde é identificada a velocidade da onda em pontos difratores, que são seções as quais denominamos seções-V. Estes pontos serão utilizados como pontos de controle no modelo de velocidades gerado pelo processamento sísmico tradicional de reflexões.

Os resultados preliminares foram mostrados em Maciel e Biloti (2010). Neste trabalho, mostramos os resultados mais atuais, e mostramos como o modelo de velocidade é construído para a migração.

\section{MÉTODOS}

As seções-D e seções- $V$ são painéis onde o eixo horizontal representa possíveis coordenadas horizontais $X_{D}$ de um difrator, e o eixo vertical representa os tempos $t_{0}$ de ida e volta de uma onda gerada por uma fonte e captada por um receptor localizados exatamente na posição acima do difrator. Para a geração das seções-V, utilizamos neste trabalho dados gerados a partir da simulação de uma aquisição sísmica de modelos sintéticos. O algoritmo de construção da seção-D envolve encontrar uma velocidade ótima para cada ponto $\left(X_{D}, t_{0}\right)$, que maximize a coerência entre o dado simulado e a curva 
de difração. Esta velocidade ótima fica registrada na seção-V.

O modelo de velocidades a ser construído deve ser suave, e conter as velocidades RMS em um painel $\xi$ versus tempo. A entrada contém pontos neste painel obtidos através da análise de velocidade tradicional de dados de reflexão, alinhados em $\xi$ por CDP's, e pontos obtidos pela $\mathrm{D}$-section, onde estão representados pontos difratores na coordenada $\xi$.

\section{Modelamento do dado}

Os dados foram gerados a partir de um modelador Kirchhoff encontrado nos pacotes do Seismic Unix, que permite definir refletores apenas pela mudança do coeficiente de reflexão em determinada profundidade. Isto permite a construção de um dado onde a velocidade do meio é toda constante, mas apresenta refletores e pontos difratores. Fisicamente podemos interpretar estes refletores como fraturas em um rocha, onde a velocidade acústica muda apenas suavemente em profundidade devido à pressão da rocha, mas a fratura pode gerar reflexão da onda. Os dados são organizados em seções de afastamento comum para melhor detecção das curvas de difração. O dado possui difrações caso haja quinas no modelo, cujo comportamento dinâmico segue o padrão exposto por Trorey. Neste trabalho apresentamos os resultados para um modelo com três refletores planos (ver Figura 3), e foi acrescido ao dado um ruído aleatório de razão sinal ruído igual a 10 .

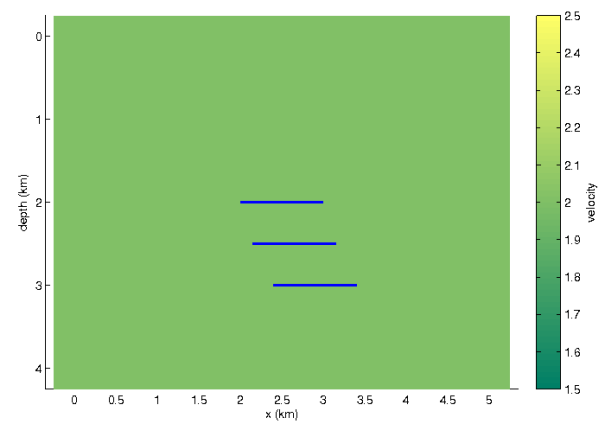

Figura 1: Modelo sintético utilizado. O meio possui velocidade constante igual a $2 \mathrm{~km} / \mathrm{s}$.

\section{Detecção de difrações}

A detecção das difrações é feita a partir da construção de um painel similar às seções-D (Landa et al., 1987). Em uma seção de afastamento comum, as difrações aparecem em curvas que obedecem à equação 1 . Como a posição do ponto médio $X_{C M P}$ é determinada pela aquisição, a curva é caracterizada pelos parâmetros $X_{D}$, $t_{0}$ e $v$, onde $v$ é a velocidade do meio. Assim é construída uma função que calcula a curva para vários valores destes parâmetros, e para cada curva, calculamos o valor da coerência dos valores coletados no dado. O resultado
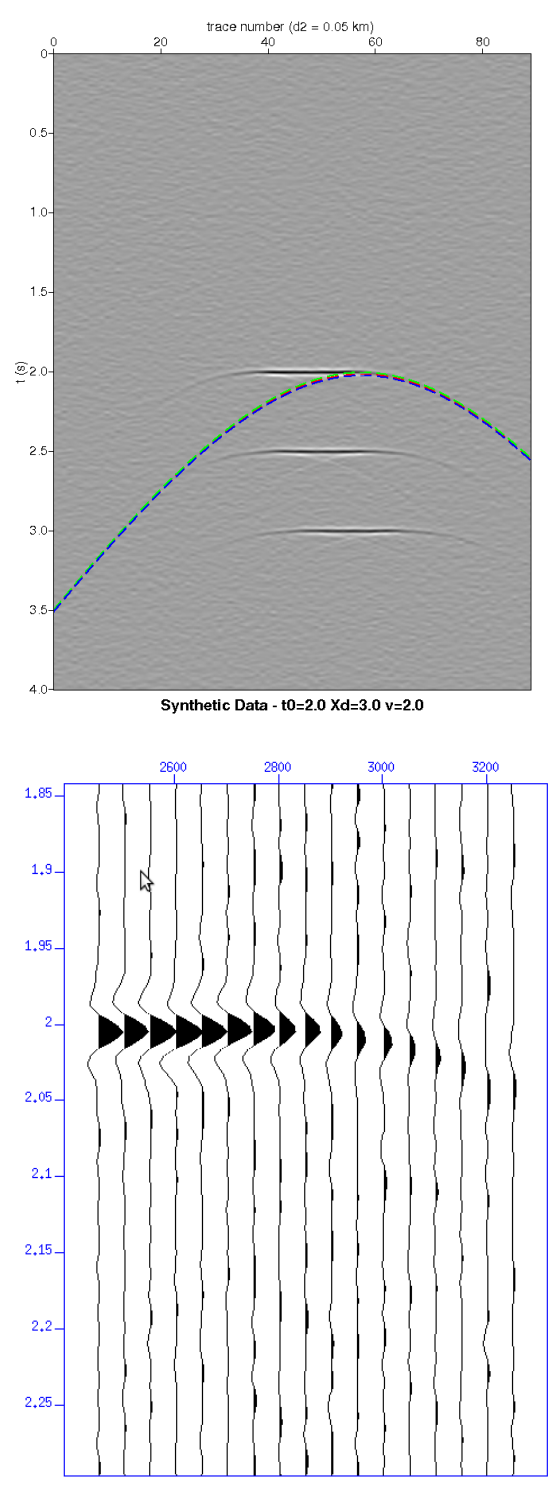

Figura 2: Seção sísmica de afastamento comum do modelo. Observe que as difrações geram curvas hiperbólicas, e que há mudança de fase e decaimento das amplitudes nas difrações.

é um painel $X_{D} \times t_{0}$ (ver Figuras 4 e 6 ) semelhante a um painel de análise de velocidades, onde a posição dos difratores é extraída por técnicas convencionais de processamento.

$$
t_{D}=\sqrt{t_{0}^{2} / 4+(\xi+h)^{2} / v^{2}}+\sqrt{t_{0}^{2} / 4+(\xi-h)^{2} / v^{2}}
$$

onde

- $t_{0}=$ tempo de trânsito de ida e volta da onda sísimica em configuração de afastamento nulo;

- $v=$ velocidade do meio; 
- $h=$ afastamento;

- $\xi=X_{C M P}-X_{D}$

- $X_{C M P}=$ coordenada horizontal do ponto médio entre fonte e receptor

- $X_{D}=$ coordenada horizontal do difrator.

- $t_{0}=$ zero offset two-way traveltime;

- $v=$ media velocity;

- $h=$ offset;

- $\xi=X_{C M P}-X_{D}$

- $X_{C M P}=$ horizontal coordinate of midpoint between source and receiver;

- $X_{D}=$ diffractor horizontal coordinate.

A velocidade que produz a maior coerência é guardada na seção-V (Figura 5). Determinada a localização das difrações na seção-D, é passado um filtro na seção-V de onde guardamos apenas as velocidades ótimas dos locais onde foram detectadas difrações. Estes locais determinam pontos de controle para o ajuste das interfaces no modelo de velocidades.

\section{Construção do modelo de velocidade}

O modelo de velocidade para a migração poderá então ser obtido a partir da análise de velocidades do processamento tradicional de reflexões. A construção das interfaces entre meios de velocidades diferentes envolve a resolução de um problema de otimização, onde a função objetivo é uma spline ajustada de maneira ótima e os pontos de controle determinados pela seção-V representam restrições a esse ajuste.

$\mathrm{O}$ ajuste pode ser feito através de uma abordagem por quadrados mínimos, e o problema pode ser definido como a solução de

$$
\begin{gathered}
\min _{V} \beta \sum_{i \in R e f}\left\|V a\left(\xi_{i}, t_{i}\right)-V_{i}\right\|^{2}+ \\
(1-\beta) \sum_{j \in D i f}\left\|V a\left(\xi_{j}, t_{j}\right)-V_{j}\right\|^{2}
\end{gathered}
$$

onde

- $V a(\xi, t)$ é a velocidade amostrada no ponto $(\xi, t)$ encontrada por alguma medida de coerência;

- $V$ é a velocidade a ser ajustada;

- $\beta$ é um coeficiente entre 0 e 1 , que dará o peso da mistura entre os modelos obtidos por dados de reflexão e difração.

\section{B-splines}

A função $V(\xi, t)$ é construída pela soma

$$
V=\sum_{k} \sum_{l} c_{k l} v_{k l}(\xi, t)
$$

onde as funções $v_{k l}(\xi, t)=B_{k}(\xi) B_{l}(t)$ são B-splines bidimensionais, e os coeficientes $c_{k l}$, por enquanto, são calculados por uma abordagem de quadrados mínimos, definida por

$$
\min _{c}\left\|V\left(\xi_{i}, t_{i}\right)-\sum_{j} c_{j} v_{j}\right\|^{2}
$$

onde

- $j=(l-1) m+k$,

- $1 \leq l \leq n$,

- $1 \leq k \leq m$.

e consideramos apenas o conjunto de pontos difratores $(\xi, t)$.

Para mesclar os dois modelos, temos que resolver o seguinte problema de otimização: minimizar a função dada por

$f: \Re^{n \times m} \rightarrow \Re$

definida por

$f(x)=\beta\|A x-b\|^{2}+(1-\beta)\|C x-d\|^{2}$

onde

- $A$ é $D \times n m$,

- $C$ é $R \times n m$,

- $b$ é $D \times 1$,

- $d$ é $R \times 1$,

- $x$ é $n m \times 1$

Este mínimo é encontrado zerando o gradiente de $f$. Como o modelo possui $\mathrm{nm}$ parâmetros, teremos $\mathrm{nm}$ equações para o gradiente:

$$
\begin{aligned}
& \frac{\partial f}{\partial x_{i}}=2 \beta \sum_{l=1}^{D}\left(\left(\sum_{k=1}^{n m} a_{l k} x_{k} a_{l i}\right)-b_{l} a_{l i}\right) \\
& +2(1-\beta) \sum_{l=1}^{R}\left(\left(\sum_{k=1}^{n m} c_{l k} x_{k} c_{l i}\right)-d_{l} c_{l i}\right)
\end{aligned}
$$


Como $\frac{\partial f}{\partial x_{i}}=0$, para $i=1, \ldots, n m$, obtemos $n m$ equações, para descobrir $n m$ variáveis $x_{i}$, e está resolvido o problema.

Em forma matricial, temos

$$
\min \left\|\left[\begin{array}{c}
\beta A \\
(1-\beta) C
\end{array}\right][x]-\left[\begin{array}{c}
\beta b \\
(1-\beta) d
\end{array}\right]\right\|^{2}
$$

Para $\beta=0$, o modelo despreza os pontos difratores e só utiliza os dados encontrados pelo processamento das ondas refletidas; para $\beta=1$, o modelo considera apenas as ondas difratadas.

\section{Exemplo}

Considere um modelo hipotético, onde foram identificados por algum processo, pontos na subsuperfície onde foi calculada a velocidade da onda acústica refletida e difratada.

Neste exemplo, velocidade da onda acústica encontrada nos pontos difratores é de $2 \mathrm{~km} / \mathrm{s}$ e nos refletores é de $3 \mathrm{~km} / \mathrm{s}$. A posição horizontal e o tempo de cada ponto é setado randomicamente entre 0 e $200 \mathrm{~km}$ e 0 a 5 segundos, respectivamente. Abaixo, na figura 3 , está ilustrado o modelo de velocidades encontrado a partir do ajuste descrito na seção anterior, $\operatorname{com} \beta=0.5$.

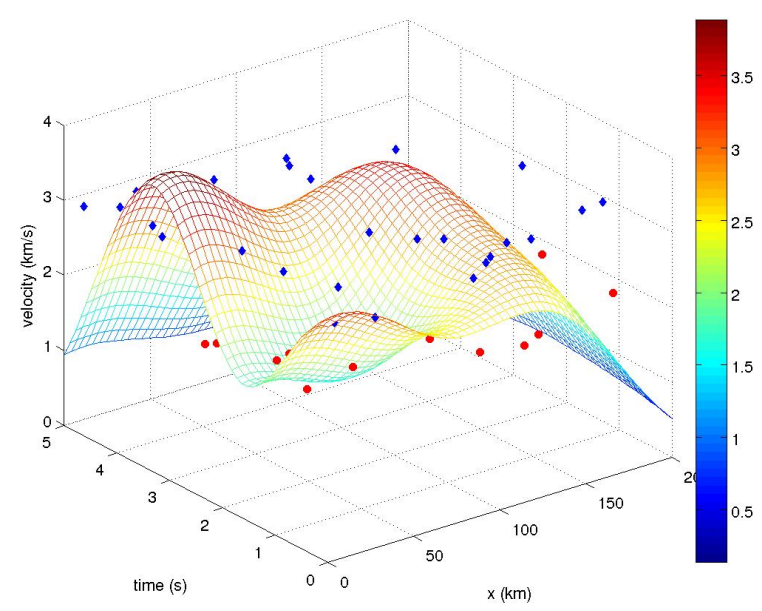

Figura 3: Modelo de velocidades encontrado a partir do ajuste por splines. Os pontos vermelhos representam a posição dos pontos difratores e os azuis, pontos onde foram detectadas velocidades a partir de análise de velocidades para curvas de reflexão.

\section{RESULTADOS}

As construções das seções-D e seções- $V$ são os principais resultados deste trabalho. A seção- $D$, inicialmente proposta por Landa et al. (1987), e a seção-V, foram repensadas e construídas em linguagem $C$, e estão disponíveis para serem utilizadas através da interface GêBR para processamento sísmico. O modelo final de velocidades é construído em Octave.

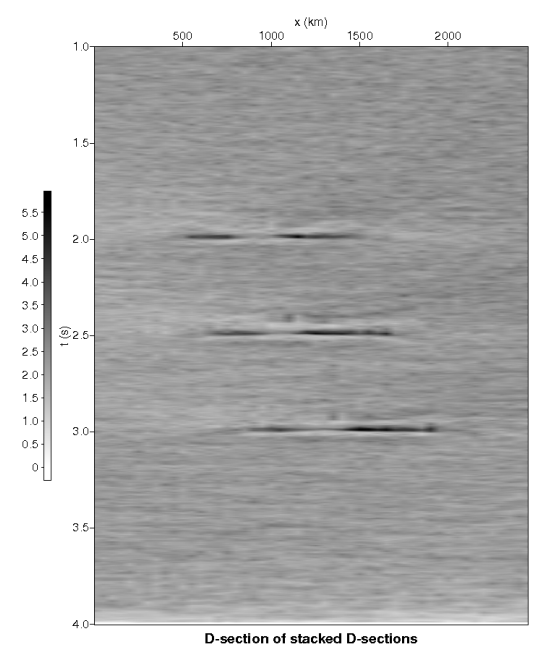

Figura 4: Seção-D do modelo. O eixo horizontal é a posição da fonte e o eixo vertical é o tempo de trânsito de ida e volta para o afastamento nulo.

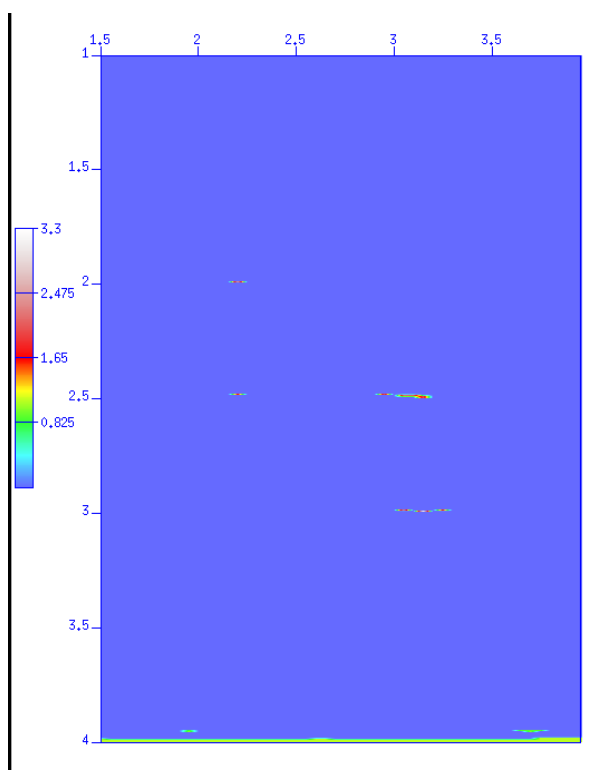

Figura 5: Seção-V do modelo. O eixo horizontal é a posição da fonte e o eixo vertical é o tempo de trânsito de ida e volta para o afastamento nulo. As manchas em vermelho indicam que naqueles pontos há difratores em meios com velocidade acústica igual a $2 \mathrm{~km} / \mathrm{s}$.

Para pequenos gradientes de velocidade, o algoritmo permanece consistente. $\mathrm{O}$ resultado pode ser visto na figura 6

\section{DISCUSSÃO E CONCLUSÕES}




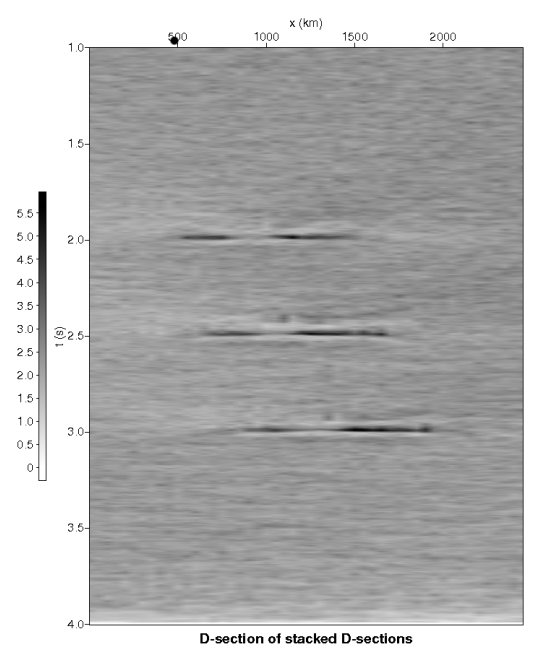

Figura 6: Seção-D do modelo com leve gradiente vertical de velocidade. O eixo horizontal é a posição da fonte e o eixo vertical é o tempo de trânsito de ida e volta para o afastamento nulo.

Propomos a otimização da construção do modelo de velocidades no processamento sísmico tradicional, utilizando as difrações como informação. Para isso, a etapa de pré-processamento é feita em duas seções distintas: a tradicional, onde as amplitudes mais baixas são filtradas, e apenas as reflexões são consideradas informação; e outra onde os eventos de difração são realçados, e os de reflexão suprimidos.

A identificação de pontos difratores em uma seção sísmica pelo uso de algoritmos de busca como a seçãoD mostrou-se precisa e eficaz, e as seções- $V$ filtradas, que são o produto final do trabalho, resgataram corretamente a velocidade utilizada nos modelos, de $2 \mathrm{~km} / \mathrm{h}$.

A construção final do modelo de velocidades é feita a partir de uma abordagem de quadrados mínimos, utilizando B-splines. Note que o ajuste dos modelos de velocidade gerado pelo processamento sísmico tradicional e pelo processamento sugerido aqui não é trivial. Os pontos onde há difrações devem corresponder a estruturas pontiagudas no modelo, respeitando o formato dos refletores identificados pelo processamento das reflexões. Para isto, é necessária a construção de uma função que otimize o ajuste da velocidade aos pontos de controle, e ainda respeite os limites estabelecidos pelos refletores identificados. Uma vez determinado o modelo de velocidade, pode ser feito qualquer tipo de migração, e espera-se que a imagem migrada mostre as difrações de forma mais nítida.

Todo o processamento, com excessão à construção da seção-D e da seção- $\mathrm{V}$, foi realizada com pacotes já estabelecidos, entre eles o Seismic Unix, do CWP, e a GêBR, que foi utilizada como interface dos programas do Seismic Unix e dos programas criados neste trabaIho. Isto indica que o procedimento pode ser adaptado a qualquer pacote de processamento, bastando acrescentar a melhoria do modelo de velocidades na etapa da migração.

\section{AGRADECIMENTOS}

Agradecemos à Rede de Geofísica Aplicada a aos patrocinadores do WIT Consortium.

\section{REFERÊNCIAS}

Fomel, S., Landa, E., e Tuner, M. T., 2007, Postack velocity analysis by separation and imaging of seismic diffractions: Geophysics, 72, no. 6, U89-U94.

Gelschinsky, B., Landa, E., e Shtivelman, V., 1985, Algorithms of phase and group correlation: Geophysics, 50, no. 4, 596-608.

Khaidukov, E., Landa, E., e Moser, T. J., 2004, Diffraction imaging by focusing-defocusing: an outlook on seismic superresolution: Geophysics, 69, no. 6, 1478-1490.

Landa, E., e Keydar, S., 1998, Seismic monitoring of diffraction images for detection of local heterogeneities: Geophysics, 63, no. 3, 1093-1100.

Landa, E., Shtivelman, V., e Gelschinsky, B., 1987, A method for detection of diffracted waves on commonoffset sections: Geophysical Prospecting, 35, 359373.

Maciel, S., e Biloti, R., 2010, Processamento sísmico de difrações: Anais do IV Simpósio Brasileiro de Geofísica, $\mathbf{1}$, no. 1,1 .

Sava, P., Biondi, B., e Etgen, J., 2005, Wave-equation migration velocity analysis by focusing diffractions and reflections: Geophysics, 70, no. 3, U19-U27. 